$\mathrm{SCIDOC}$

\section{International Journal of Dentistry and Oral Science (IJDOS) ISSN: $2377-8075$}

\title{
Dentition Status Of Outpatients Of Different Age Groups - An Observational Study
}

Research Article

Vigneshwaran Ravichandran ${ }^{1}$, Jayashri Prabakar ${ }^{*}$, Manjari Chaudhary ${ }^{3}$

${ }^{1}$ Saveetha Dental College, Saveetha institute of medical and technical sciences (SIMATS), Saveetha university, Chennai, India.

${ }^{2}$ Department of Public Health Dentistry, Saveetha Dental College and Hospitals, Saveetha Institute of Medical and Technical Sciences, Saveetha University, Chennai, India.

${ }^{3}$ Department of Oral medicine and Radiology, Saveetha Dental College and Hospitals, Saveetha Institute of Medical and Technical Sciences, Saveetha University, Chennai, India.

\section{Abstract}

Oral health is a critically overlooked component of overall health and well being. Oral health has significant impact on the quality of life. Dental diseases are universal in nature. The presentation of caries can be variable. Neglect of oral diseases can largely lead to loss of tooth and also negatively affect the quality of life. This study aims to assess the dentition status and the prevalence of caries among outpatients of different age groups reporting to Saveetha dental college, Chennai . In order to assess dental caries, Decayed - Missing - Filled Teeth index [DMFT Index] were taken into consideration. The case sheets of all the Patients of OP Department of Saveetha dental college for the period of two months [DEC 2019 and JAN 2020] were collected from The data of 86, 000 patients visited Saveetha dental college during the time period of June 2019 to March 2020. Among the reviewed data , 490 appropriate study samples were selected and tabulated. Then the tabulated data was transferred to statistical analysis software SPSS . The variables were defined and the data was statistically analysed. The study sample consisted of 490 cases of which $60.2 \%$ were Male and $39.8 \%$ were Female. $45.3 \%$ of the subjects were 20 to $25 \mathrm{yrs}$ old and $54.7 \%$ of the subjects were 25 to $30 \mathrm{yrs}$ old. The mean DMFT score was found to be more among Female subjects than Male subjects and was statistically significant using Independent $\mathrm{T}$ Test. Thus the mean DMFT value for Female subjects is greater than the mean DMFT values of the Male subjects. Therefore, the prevalence of dental caries is more in Female population. Based on the findings, it can be concluded that dental caries were found to be more prevalent among Females than Males.

Keywords: Oral Health; Dentition Status; Dental Caries; DMFT; Health Education.

\section{Introduction}

Oral health is a critically overlooked component of overall health and well being. It has high significance on the quality of life [13], appearance and self - esteem [14]. Dental disease may cause restriction of activities in school, work \& home. Dental diseases significantly diminishes the quality of life for many children [21] and adults, especially those who are of low - income or are uninsured [28].

Oral diseases are the most common of the chronic diseases and are important public health problems because of their prevalence, their impact on individuals and society, and the expense of their treatment. Dental diseases are universal in nature [16]. The presence and severity may vary from one individual to another and is also affected by multiple factors such as Gender, Knowledge, Attitude, the affordability to dental/oral care [7, 12] and other factors like mineralisation of enamel [13], disasters [8], diet hygiene [10] and habits [5].

Tooth is in a constant state of demineralization and remineralization between the tooth and surrounding saliva. Demineralization occurs faster than remineralization When the $\mathrm{pH}$ at the surface of the tooth drops below 5.5 which causes decay [4, 22]. Several different treatments modalities can be used to restore teeth to proper form , function and aesthetics $[18,6]$ such as fluoride application [11] and sealants [9, 19, 20]. The preventive prophylactic

\section{*Corresponding Author:}

Dr. Jayashri Prabakar,

Department of Public Health Dentistry, Saveetha Dental College and Hospitals, Saveetha Institute of Medical and Technical Sciences, Saveetha University, Chennai, India E-mail: jayashri.sdc@saveetha.com

Received: September 07, 2020

Accepted: September 29, 2020

Published: September 302020

Citation: Vigneshwaran Ravichandran, Jayashri Prabakar, Manjari Chaudhary. Dentition Status Of Outpatients Of Different Age Groups - An Observational Study. Int J Dentistry Oral Sci. 2020;S7:02:005:20-23. doi: http://dx.doi.org/10.19070/2377-8075-SI02-07005

Copyright: Jayashri Prabakar 2020 . This is an open-access article distributed under the terms of the Creative Commons Attribution License, which permits unrestricted use, distribution and reproduction in any medium, provided the original author and source are credited. 
measures, such as regular oral hygiene and dietary modifications $[15,21]$, helps to reduce dental caries [3]. The presentation of caries can be variable; though the risk factors and stages of development are similar. Initially, it appears as a small chalky area which gradually develops into large cavitations. Sometimes caries may be directly visible. However other methods of detections such as radiographs are used for less visible areas of teeth and to judge the extent of destruction. Neglect of oral diseases can largely lead to loss of tooth and also negatively affect the quality of life led by the person due to inability to chew, speak and also unpleasant esthetics [26]. In India, dental services are provided by both public and private sector, yet due to brain drain and improper distribution of health - care workers, oral health is still at the back foot [27].

This research was needed to assess the dentition status and treatment needs of the patients. The motive of this study is to provide information to the health care authorities. This may help them to provide and plan appropriate prevention and treatment programs for school children.

The aim of this study was to assess the dentition status and the prevalence of caries among outpatients of different age groups reporting to Saveetha dental college, Chennai, India. In order to assess dental caries, Decayed - Missing - Filled Teeth Index [DMFT Index] were taken into consideration.

\section{Materials And Methods}

The present record based study was done in a university setting in Saveetha dental college, Chennai, India. The observational study was done by two examiners and the approval for this study was obtained from the Institutional ethics committee, Saveetha University, SDC/SIHEC/2020/DIASDATA/0619-0320.

The study was done for a period of 2 months (Dec 2019 to Jan 2020) with Type - 3 examination procedure. 520 case sheets were reviewed. Photographic verification was done for cross verification of the data for errors and simple random technique was followed to minimise sampling Bias. Assessment of dental caries was carried out using decayed, missing, and filled teeth (DMFT) index by Klein, Palmer, Knutson for permanent dentition. The tooth was considered carious (D component) if there was visible evidence of a cavity, including untreated dental caries. The missing ( $\mathrm{M}$ component) included teeth with indications for extractions or teeth extracted due to caries. The filled (F component) included filled teeth.
The Case sheets of all the Patients in OP Department of Saveetha dental college for the period of two months [DEC 2019 and JAN 2020] were collected from the data of 86,000 patients visited Saveetha dental college during the time period of June 2019 to March 2020. The obtained data were tabulated and entered in the MS excel sheet. The incomplete or censored data was managed by telephonic communication. The data was imported to SPSS and the variable definition process was done using tables and graphical illustration. By using the statistical software IBM SPSS Version 20.0. Statistical tests like descriptive statistics test and inferential statistics were done by keeping demographics, such as age, gender as independent variables and DMFT index scores as dependent variables. The results were expressed by means of Mean,Standard deviation \& Percentage. Independent t-test and one-way ANOVA were used to compare the mean difference. The level of statistical significance was set at a value of $\mathrm{P}<0.05$

\section{Results And Discussion}

The Quality of life is increasingly acknowledged as a valid, appropriate and significant indicator of service need and intervention outcomes in contemporary public health research and practice. Assessing the consequences of impaired oral health from the patient's perspective has emerged as an important research area. The prevention of dental caries has long been considered as an important task for the dental health profession. Scientific research studies continue to make progress in identifying the best practices for diagnosing, treating, and preventing dental caries in our world communities. Conventional approaches for treating carious lesions in a surgical manner are being replaced by newer strategies that emphasize disease prevention and conservation of tooth structure.

In the present study, 520 case sheets from DIAS data were reviewed and 490 subjects were obtained for study which were all the patients of OP Department in Saveetha Dental College for a time period of two months ( Dec 2019 and Jan 2020). The study sample consisted of 490 cases of which $60.2 \%$ were Male and $39.8 \%$ were Female. $45.3 \%$ of the subjects were 20 to 25 yrs old and $54.7 \%$ of the subjects were between 26 to $30 \mathrm{yrs}$ old (refer Figure 1 and 2).

The mean DMFT score for Male was $5.69 \pm 2.98$ and the mean DMFT score for Female was $6.64 \pm 4.02$ and was found to be statistically significant $(\mathrm{p}<0.05)$ using Independent $t$ test (refer Figure 3). The mean DMFT score for the Female population was

Figure 1. Distribution of study subjects based on Age The pic chart represents the distribution of the study population based on Age. Among the total study population (490), 268 (54.7\%) were 26 to 30 yrs old and $222(45.3 \%)$ were 20 to 25 yrs old.

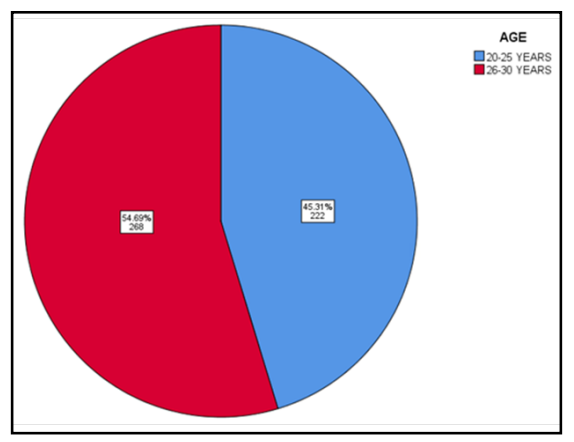


Figure 2. The bar graph represents the distribution of study subjects based on Gender. Among the total study population (490) , 295 (60.2\%) were Male and $195(39.8 \%)$ were Female.

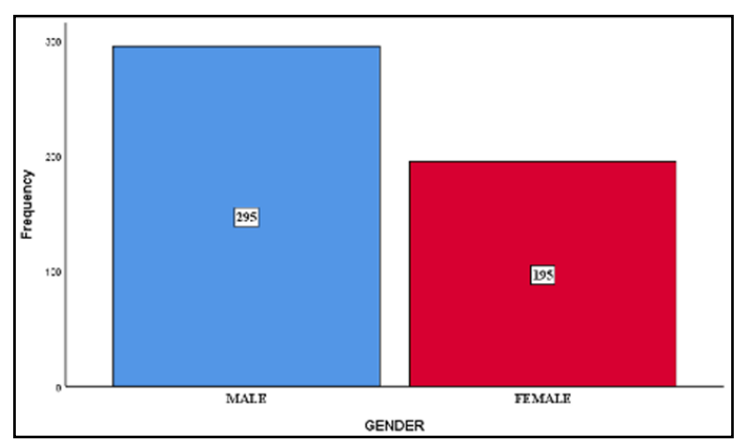

Figure 3. The bar graph represents the Comparison of Mean DMFT with the Gender of the Patients . The mean DMFT score for Male was 5.69 \pm 2.98 and the mean DMFT score for Female was $6.64 \pm 4.02$ and was found to be statistically significant using Independent $t$ test $(\mathrm{p}<\mathbf{0 . 0 5})$.The mean DMFT score for the Female population was greater than the Male population.

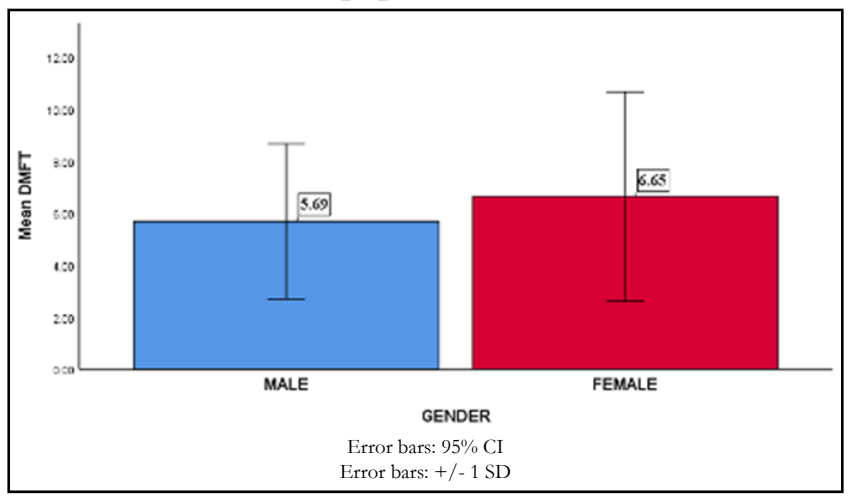

Figure 4. The bar graph represents the Comparison of Mean DMFT with the Age of the Patients. The mean DMFT score for the subjects between 20 to 25 yrs was $6.0 \pm 3.68$ and the mean DMFT score for the subjects between 26 - 30 yrs was 6.12 \pm 3.28 and was found to be statistically insignificant $(p>0.05)$ using the Independent $t$ test.

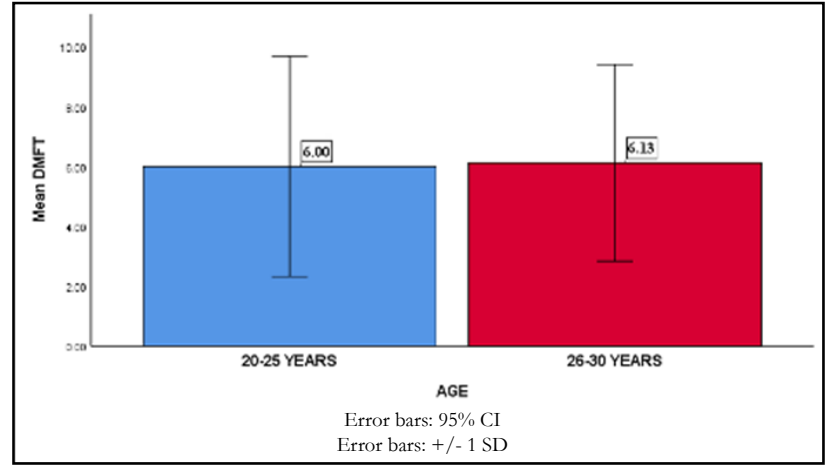

greater than the Male population, thus the dental caries was more prevalent in Females as compared to Male population. Therefore the dentition status of Female population was worse than that of the Male population as per the present study.

It was a proven fact that oral diseases greatly affect the quality of life $[12,23]$. The dentition status had a strong association between Pain, Discomfort, Stress, Irritability and Functional disability with the decayed and missing component of DMFT Index.

The study of [25] had similar findings with the present study which includes that the prevalence was more in females as compared to Males. Also the study [24] had similar findings that $\mathrm{Fe}$ males were more prevalent to dental caries than Males.

On the other hand, the study of [1], have opposing findings that Males were slightly more affected than Females. The study [2] also have opposing findings that Males were more prevalent to Dental caries than Females. This opposing finding was because of the personal hygiene of the study subjects.

The mean DMFT score for the subjects between 20 to 25 yrs was $6.0 \pm 3.68$ and the mean DMFT score for the subjects between 26 - 30 yrs was $6.12 \pm 3.28$ and was found to be statistically insignificant $(\mathrm{p}>0.05)$ using Independent t test (refer Figure 4). The previous study (2) shows similar findings with our present study.

\section{Limitations}

The present study had certain limitations . The overall population was not included for this study. Assessment of the entire population under this limited age group was not done in the present study to conclude the caries prevalence. 


\section{Future scopes}

Future scopes like administration of health education and organization of health intervention programmes should be conducted . Further studies are essential to reveal the impact of the interventions on oral health status and also the quality of life.

\section{Conclusion}

As oral health often appears to be a low priority issue for Government and health policy makers, oral health care professionals should be at the forefront advocating for resource mobilization to improve access to appropriate oral health care for the population. The present study highlighted the dentition status and the prevalence of dental caries among the population. From the analysis of the present study, Prevalence of dental caries was more in Females as compared to Males.

\section{References}

[1]. Aggarwal T, Goswami M, Dhillon JK. Assessment of Oral Health Educational Program on oral health status of visually impaired children in New Delhi. Spec Care Dentist. 2019 Mar;39(2):140-146. Pubmed PMID: 30648764.

[2]. Agrawal M, Agrawal S, Anuradha P, Dutta SD, Sharma A, Gupta M, et al. Dentition status and treatment needs of engineering students in Lucknow city. Journal of Indian Association of Public Health Dentistry. 2014 Oct $1 ; 12(4): 272$.

[3]. Bali RK, Mathur VB, Talwar PP, Chanana HB. National oral health survey and fluoride mapping 2002-2003 India. New Delhi: Dental Council of India. 2004;132.

[4]. Bratthall D. Estimation of global DMFT for 12-year-olds in 2004. Int Dent J. 2005 Dec;55(6):370-2. pubmed PMID: 16379140.

[5]. Leelavathi L. Nicotine Replacement Therapy for Smoking Cessation-An Overview. Indian Journal of Public Health Research \& Development. 2019 Nov $1 ; 10(11)$.

[6]. Kaimenyi JT. Oral health in Kenya. International Dental Journal. 2004 Dec $1 ; 54: 378-82$

[7]. Kalaskar RR, Kalaskar AR, Chandorikar H, Hazarey S. Prevalence of dental caries and treatment needs in school going children of Vidarbha region, central India. Univ Res J Dent. 2015 Aug;5(2):68-72.

[8]. Kannan, S. S. D. et al. (2017) 'Awareness And Attitude Towards Mass Disaster And Its Management Among House Surgeons In A Dental College And Hospital In Chennai, India', Disaster Management and Human Health Risk V. doi: $10.2495 /$ dman 170121.

[9]. Khatri SG, Madan KA, Srinivasan SR, Acharya S. Retention of moisturetolerant fluoride-releasing sealant and amorphous calcium phosphate-containing sealant in 6-9-year-old children: A randomized controlled trial. J Indian Soc Pedod Prev Dent. 2019 Jan-Mar;37(1):92-98. Pubmed PMID: 30804314

[10]. Kumar RP, Preethi R. Assessment of water quality and pollution of Porur, Chembarambakkam and Puzhal Lake. Research Journal of Pharmacy and Technology. 2017 Jul 1;10(7):2157-9.

[11]. Kumar RP, Vijayalakshmi B. Assessment of fluoride concentration in ground water in Madurai district, Tamil Nadu, India. Research Journal of Pharmacy and Technology. 2017;10(1):309.
[12]. Mathew MG, Samuel SR, Soni AJ, Roopa KB. Evaluation of adhesion of Streptococcus mutans, plaque accumulation on zirconia and stainless steel crowns, and surrounding gingival inflammation in primary molars: randomized controlled trial. Clin Oral Investig. 2020 Sep;24(9):3275-3280. Pubmed PMID: 31955271.

[13]. Mohapatra S, Kumar RP, Arumugham IM, Sakthi D, Jayashri P. Assessment of Microhardness of Enamel Carious Like Lesions After Treatment with Nova Min, Bio Min and Remin Pro Containing Toothpastes: An in Vitro Study. Indian Journal of Public Health Research \& Development. 2019 Oct $1 ; 10(10)$.

[14]. Mosha HJ. Provision of oral health care services in Tanzania: implementation status (2005). Tanzania Dental Journal. 2005;12(1):30-4.

[15]. Neralla M, Jayabalan J, George R, Rajan J, P SKM HA. Role of nutrition in rehabilitation of patients following surgery for oral squamous cell carcinoma. International Journal of Research in Pharmaceutical Sciences. 2019 Oct 16;10(4):3197-203

[16]. Patil S, Doni B, Kaswan S, Rahman F. Prevalence of dental anomalies in Indian population. J Clin Exp Dent. 2013 Oct 1;5(4):e183-6. Pubmed PMID: 24455078.

[17]. Jayashri P, Sharma SG, Sharma M, Guleria P. Influence of naturally occurring phytochemicals on oral health. Research Journal of Pharmacy and Technology. 2019 Aug 1;12(8):3979-83.

[18]. Prabakar J, John J, Arumugham IM, Kumar RP, Srisakthi D. Comparative Evaluation of Retention, Cariostatic Effect and Discoloration of Conventional and Hydrophilic Sealants - A Single Blinded Randomized Split Mouth Clinical Trial. Contemp Clin Dent. 2018 Sep;9(Suppl 2):S233-S239. Pubmed PMID: 30294150.

[19]. Prabakar J, John J, Arumugham IM, Kumar RP, Sakthi DS. Comparative Evaluation of the Viscosity and Length of Resin Tags of Conventional and Hydrophilic Pit and Fissure Sealants on Permanent Molars: An In vitro Study. Contemp Clin Dent. 2018 Jul-Sep;9(3):388-394. Pubmed PMID: 30166832.

[20]. Prabakar J, John J, Arumugham IM, Kumar RP, Sakthi DS. Comparing the Effectiveness of Probiotic, Green Tea, and Chlorhexidine- and Fluoride-containing Dentifrices on Oral Microbial Flora: A Double-blind, Randomized Clinical Trial. Contemp Clin Dent. 2018 Oct-Dec;9(4):560-569. Pubmed PMID: 31772463.

[21]. Prabakar J, John J, Srisakthi D. Prevalence of dental caries and treatment needs among school going children of Chandigarh. Indian J Dent Res. 2016 Sep-Oct;27(5):547-552. Pubmed PMID: 27966516.

[22]. Pratha AA, Prabakar J. Comparing the effect of Carbonated and energy drinks on salivary pH-In Vivo Randomized Controlled Trial. Research Journal of Pharmacy and Technology. 2019 Oct 1;12(10):4699-702.

[23]. Samuel SR, Acharya S, Rao JC. School Interventions-based Prevention of Early-Childhood Caries among 3-5-year-old children from very low socioeconomic status: Two-year randomized trial. J Public Health Dent. 2020 Jan;80(1):51-60. Pubmed PMID: 31710096.

[24]. Shenoy RP, Hegde V, Shenai PK. Dentition status, treatment needs and dental aesthetic index scores of individuals attending special schools. Indian J Community Med. 2011 Oct;36(4):301-3. Pubmed PMID: 22279262.

[25]. Shingare P, Jogani V, Sevekar S, Patil S, Jha M. Dental caries prevalence among 3 to 14 year old school children, Uran, Raigad district, Maharashtra. J Contemp Dent. 2012 May;2(2):11-4.

[26]. Sussex PV. Edentulism from a New Zealand perspective--a review of the literature. N Z Dent J. 2008 Sep;104(3):84-96. Pubmed PMID: 18980049.

[27]. Tandon S. Challenges to the oral health workforce in India. J Dent Educ. 2004 Jul;68(7 Suppl):28-33. Pubmed PMID: 15282249.

[28]. Tewari A, Chawla HS. Study of prevalence of dental caries in an urban area of India (Chandigarh). J Indian Dent Assoc. 1977;49:231-9. 